\title{
Reseña
}

\section{Spoilers del presente. Ver series para ser de nuestra época}

Spoilers del presente. Ver series para ser de nuestra época | Juan Pablo Duarte (comp.)

| Ediciones Universidad Nacional de Córdoba | 2021

\section{Lorena Beloso*}

Universidad Católica de las Misiones

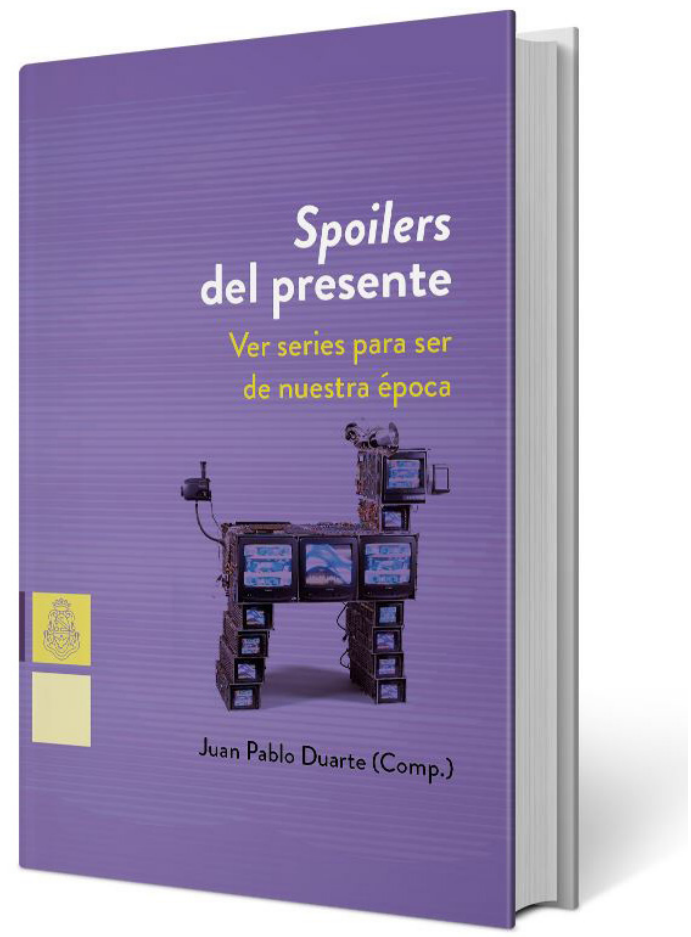

Quienes amamos el cine y las series, cuando leemos sobre eso, estamos siempre atentos a una advertencia común y necesaria: "este artículo contiene spoilers".

Aviso que puede determinar si avanzamos o no. Pero esta vez, no estamos en presencia de algo tan simple. Un título, nos interpela ¿Se puede spoilerar el presente? ¿En una suerte de anticipación? ¿Se trata de adivinarlo? ¿De interpretarlo sobre la marcha? Escribo estas preguntas antes de comenzar a leer el libro. Veamos.

La primera clave la brinda Juan Pablo Duarte en el "Trailer", nos dice "posiblemente las series sean una de las respuestas más originales a un momento histórico en el que la verdad se transformó en una ficción en crisis" (p. 11), así se trata de un "presente que el pasado no permite situar" (p. 11). Advierte que son aquellos sucesos actuales, que no llegan a nombrarse del todo, que no pueden clasificarse por completo o incluso cuentan con características inéditas y que "casi en simultáneo las series intentan escribirlas" (p. 13) y entonces "su retrato de la realidad aspira menos a una fidelidad factual que a señalar lo que el presente contiene de indecible. En las series, en las más serias entre ellas, este fracaso impulsa su insistencia" (p. 13). Wow. Cuando un tráiler nos engancha, no tardamos en comenzar un maratón, y este parece ser el caso.

* lorenabeloso@gmail.com 


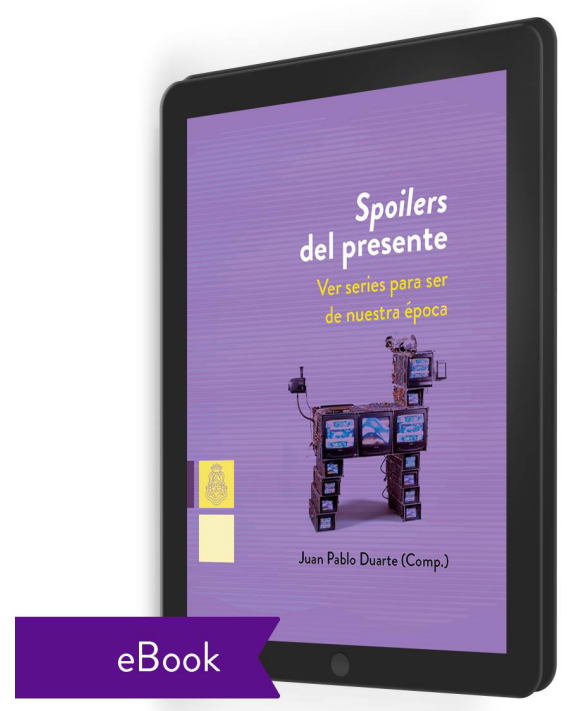

\section{¡Continuemos!}

El primer episodio es central, es algo que nos enseñó Trwin Peaks ${ }^{1}$ y quienes trabajaron en la edición de este libro al parecer lo saben muy bien. Comenzar a plasmar la temática con Don Draper en la pluma de Jorge Assef, es una apuesta segura. Con su estilo tan particular, visibilizando esos detalles que se nos escapan y a los cuales nos invita a remitirnos, resalta la relación de los sujetos contemporáneos con los objetos de goce y su indiferenciación y así, cómo un relato situado en los años sesenta puede enseñarnos sobre nuestro tiempo. Listo, nos atrapó.

Desde allí, encontramos una primera respuesta. Sí, se puede spoilear el presente. En nuestras pantallas tenemos ese efecto de verdad mediodicha y escenificada, ese borde entre la ficción y lo cotidiano. Lo que puede ser mostrado y nos orienta a pensar la actualidad, de lo cual se sirven psicoanalistas y figuras de la cultura para escribir al respecto.

Avanzamos y nos encontramos con un sin fin de interpretaciones, comentarios e incluso interrogantes que nos hacen pensar en Netflix, Amazon Prime y en nosotros mismos de otra manera.

De lo macro de los debates actuales, como la rela- ción entre las tecnologías y el poder, y las tensiones entre el estado y el capital, este libro propone una "operación lacaniana de lectura" ${ }^{2}$ centrándose en lo que escapa a la lógica universal, y es creo, lo que permite pesquisar los efectos de aquello en los sujetos de nuestro tiempo. Entonces, ¿lo que vemos en las series, podemos escucharlo en nuestros consultorios?

Estos autores nos responden desmenuzando las grandes temáticas que han atravesado la humanidad desde siempre, como el amor y sus enredos, las angustias, la violencia, los autismos contemporáneos, resaltando las contradicciones inherentes a las relaciones humanas y la diferencia entre lo verdadero y lo real.

Al finalizar el maratón de capítulos hay un "extra" que no quiero spoilear, solo diré que se elige terminar con el registro de una actividad que permitió transitar la pandemia de otro modo. Porque hay que decirlo, estos textos fueron pensados, escritos y editados en un momento universal único, donde para muchos lo que permitió sobrellevar la situación fueron los libros, el psicoanálisis y las series. Aunque ya en otras circunstancias, ¡esperaremos ansiosos las próximas temporadas de Spoilers del Presente!

\section{Referencias}

Duarte, J. P. (2021). Spoilers del presente. Ver series para ser de nuestra época. Editorial Universidad Nacional de Córdoba.

\footnotetext{
(Lynch, 1990)

(Fernández, 2021, p. 66)
} 